\title{
Looking at Reflection within a Community of Practice of RTLBs
}

\author{
Ivanka Soljan \\ Resource Teacher: Learning and Behaviour, Tuawhitu o Akarana Cluster, Central Auckland \\ Yvonne Stanghan \\ Resource Teacher: Learning and Behaviour, Manawanui Cluster, Papatoetoe/Otara
}

Anna Henry

Resource Teacher: Learning and Behaviour, Practice Leader for Cluster 9, Mangere/Otahuhu, South Auckland

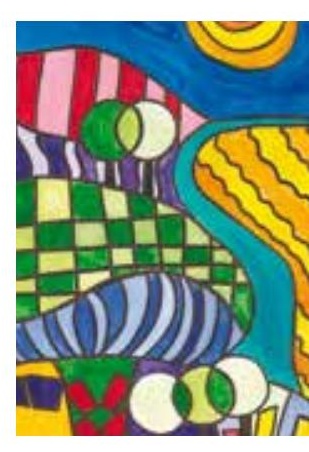

\begin{abstract}
The term 'reflection' is defined as a contemplation of one's teaching craft with the view to improving it (Edwards \& Thomas, 2010). Reflection is supported by a number of theories and is considered a key component of RTLB work. A community of practice $(\mathrm{CoP})$, when used as a space for reflection, provides the potential for multiple and critical lenses to examine practice and enables a deeper, clearer understanding of casework. This article discusses some of the theory relating to reflection, positions reflection within a community of practice, and illustrates how it can be applied in the RTLB context.
\end{abstract}

\section{Practice Paper}

Keywords: Community of Practice, professional practice, reflection

\section{INTRODUCTION}

It has long been accepted that a good teacher is a reflective teacher, and indeed reflection has been woven into contemporary professional practice (The New Zealand Teachers Council, 2009). Similarly, for Resource Teachers: Learning and Behaviour (RTLB), reflection is now one of the seven fundamental principles that guide practice (Ministry of Education, 2011). The RTLB Toolkit (2011) describes the principle as "recognising and valuing the importance of evaluating practice for future improvement" (p. 31). RTLB are expected to reflect on the match between their behaviour and intentions, the effectiveness of outcomes, the outcomes for student, whānau and community, and all with reference to established theory. How this translates into practice is dependent on individual preference and on specific systems defined by cluster management. This article outlines some of the theory that supports reflective practice and then foregrounds how reflection can be incorporated into the RTLB workplace through a community of practice.

Edwards and Thomas (2010) define reflective practice for teachers as the process through which teachers contemplate their teaching practice with the view to improving it. Much of the literature that supports teacher reflection is theory-driven rather than researchbased. Dewey (1933, cited in Scales (2008, p. 10) was one of the first educationalists to highlight the value of incorporating reflective thinking into professional practice. He discussed the idea of moving from routine action to reflective action which is characterised by on-going self-appraisal and development. Schön (1987) was most influential in incorporating reflection into practice for the modern day. His theory focused on two actions: reflection on action and reflection in action. Reflection on action refers to thinking about one's practice after the fact, while reflection in action refers to the ability to "evaluate, assess and act in order to shape on-going activity in the moment" (Enfield \& Stasz, 2011, p. 113). According to Schön (1987), the mark of a professional is the ability to anticipate outcomes, and reference multiple criteria to reshape action. Both types of reflection are essential activities for teachers, and Schön adds to these by differentiating between technical knowledge and tacit knowledge. He describes technical knowledge as the theoretical learning of classroom practice, the understanding of the teaching craft. Technical knowledge and understanding do not always play out in practice, as some actions teachers take are based on beliefs that have been built through experience over time. These beliefs are often unexamined or tacit, and some are supportive of student learning, while others are not. It is argued that reflection helps teachers examine their tacit understandings, and brings to light some of the unseen reasons behind their action (Ross, Bondy \& Kyle, 1993).

Larrivee (2000) takes the concept of tacit understandings a step further by making the point that effective teaching is more than a compilation of skills and strategies: it is a "deliberate philosophical and ethical code of conduct" (p. 294). She encourages teachers to critically reflect on their practice and highlights that teachers need to examine personal and professional belief-systems, and to 
consider the ethical implications of their practice. As all experiences are fashioned by society and culture, teachers make judgements that are influenced by their culture and personal biases. Becoming a criticallyreflective practitioner requires teachers to examine deeply-rooted beliefs concerning human nature, human potential, and human learning, and to question assumptions and existing practices, thereby accessing a new lens that alters perspectives (Larrivee, 2000). This process can lead to a state of dissonance where there is a gap between prior beliefs and new learning. If teachers are able to reconcile this sense of uncertainty it can help create new ways of thinking and reframe values out of which new practices can emerge (Larrivee, 2000).

As reflection is a fundamental principle for practice, how does this play out in the RTLB role? The RTLB practice sequence (Ministry of Education, 2011) easily lends itself to reflection. It is essentially the final step in the sequence and is akin to Schön's (1987) reflection on action. The practice sequence also allows for reflection in action as, although not explicitly stated, many of the stages encourage RTLB to analyse data, context and wider social perspectives. The model allows for technical and critical reflection. The question arises as to how RTLB ensure that the reflective element provided for in the model is incorporated in practice. One way that this could be facilitated is through a community of practice (CoP) approach. A CoP is defined by Wenger (2009) as a group of people who share a concern or a passion for something they do and learn how to do it better as they interact regularly. This description perfectly captures the community of practice referred to in the rest of this article.

\section{The Birth of A Community of Practice}

The CoP came about through the new study requirements for RTLB, a two-year postgraduate diploma in specialist teaching. As the study was mostly conducted on-line, a group of students situated geographically in the same region decided to meet regularly face-to-face to discuss their learning and to review assignments. It was felt that face-to-face interactions were needed to enhance understanding. Initially, the CoP was informal, meeting together once a term to chat and 'unpack' study concerns. The attendees grew in number and it became difficult to cover all contributions in the allotted time, therefore meetings became formalised with an agenda and minutes. During this time, the meetings continued to focus on RTLB study and workload. Issues and ideas were discussed, questions were raised and solutions offered. In this phase, the talk was about refining ideas and concepts. It was a highly creative exercise and reflections would occur randomly both throughout the process, and after the fact.

As the first year of study came to an end the CoP intended to continue for the second year, however the RTLB transformation impacted the members' ability to fully commit due to work and cluster expectations. That left four of the original members. These residual participants decided to meet together with a focus of exploring different methods of peer support and feedback. The Dynamic Ecological Analysis model (DEA) (Hannant, Lim \& McAllum, 2010) was chosen as a way of achieving this. The model involves practitioners sharing, with a group of professionals, a difficult case in which they have reached an impasse in their analysis, and are unsure of what to do next. The team pose questions around the data presented and offer reasons as to why they have asked those questions. Information is accumulated through the questioning process, and at its conclusion, the RTLB is hopefully provided with an overview of the case, potential assessment gaps that may need filling and a pathway for the next steps. The questioning nature of this model encourages individuals to think critically about each other's cases, while simultaneously reflecting on their own work. This format has potential to encourage both critical reflection and technical reflection.

\section{The Reflective Hub:}

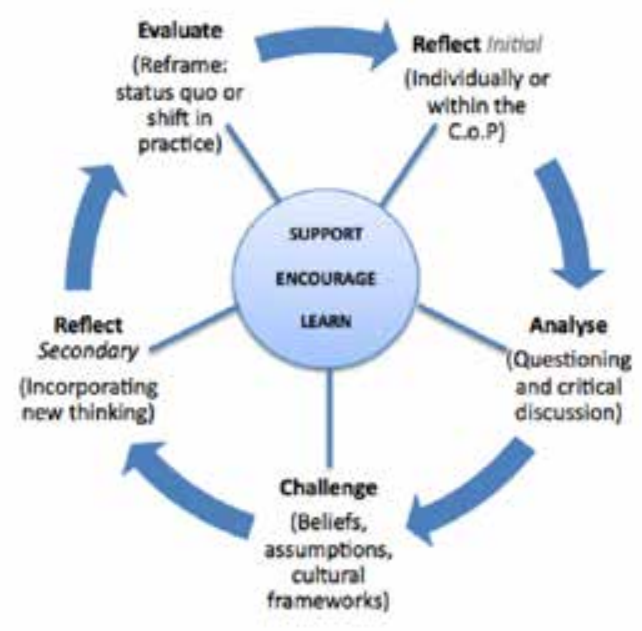

\section{Figure 1: Reflective Hub}

The Reflective Hub (Figure 1) is a visual representation of how the CoP and reflective processes combine to reframe thinking, actions and beliefs. Though the hub is designed in a cyclical manner, it is not intended to be a prescribed flow, as one can move in and around each phase through the centre of the hub. The core values of the CoP are included in the centre 
of the model. These are to learn, to support, and to encourage, and are considered to be at the heart of the CoP process. The outer cycle is viewed as the learning framework.

The initial reflection phase can be initiated by an individual's experience or can result from a discussion that has taken place within a CoP meeting. This is aligned to Schön's (1987) reflecting in action and on action. By using questioning, the analysis and challenge phases ensure the issues are critically examined and reflected upon through multiple lenses, which can help to uncover tacit beliefs. Following that, the individual considers the new ideas, hence prompting a second form of reflection. They then evaluate whether there needs to be a shift in practice or whether the status quo should remain.

The advantage of looking at reflective practice in this way is that it provides structure for reflection, while still allowing for flexibility within the application of the approach. All individuals have a personal bias; therefore there may be a danger of missing the critical nature of reflection. Having a structure to follow highlights areas that may be overlooked due to selective filters. The hub helps remind us to consider beliefs and assumptions that underpin practice in a group setting. The key is being deliberate about the nature of the analysis, discussion and reflection and ensuring that there is a critical element to it. As filters are challenged and alternative responses are considered, practitioners become open to more possibilities and all responses are examined (Larrivee, 2000).

The hub, while providing structure, also enables flexibility. There is an organic nature to it. The CoP provides a space for dialogue that is centred around the narratives of the students with whom RTLB work. The nature of the hub means that these stories can ebb and flow through the different phases, and not be tied into any particular pattern or arrangement. It becomes a more holistic, fluid process.

\section{Does a Community of Practice Assist with Reflective Practice?}

A community of practice has the potential to be a highly effective means of promoting quality reflective practice. The feedback from the CoP participants reinforced this view. As one member stated, "the collective voice is always more powerful than a single thought" (CoP member, 30 August, 2012). Through engaging in this experience a number of advantages were identified.

Sharing experiences within a group enables the members to learn from, and co-construct ideas with, their peers (Reynolds, 2011). The CoP format reinforces Vygotsky's (1978, cited in Pollard, 1997) view of the social nature of learning. The act of sharing all facets of study and casework enabled a collective evaluation of practice, which strengthened each individual's understanding of their work.

One of the advantages of reflection within a CoP, which is also related to the co-construction of learning, is the provision of multiple viewpoints. One of the critiques of self-reflection is that it is difficult for people to see 'outside' of themselves, as they don't know what they don't know. Our own beliefs and assumptions lead us to draw conclusions based on selected observation. Argyris (1990, cited in Larrivee, 2000) calls this the reflexive loop, a circular process by which we select data, add personal meaning, and make assumptions based on our interpretations of that selected data. We stay in the loop, and our beliefs stay hidden and unexamined. The CoP enabled us to see 'outside' of ourselves, and to recognise that experience is "culturally and personally sculptured" (Larrivee, 2000, p. 296). It provides multiple lenses through which an experience can be explored and possibly redefined. This was evidenced through a story related by one CoP member when discussing a negative reaction they had experienced whilst working with a parent. The parent who had initially been supportive, unsettled the RTLB by doing an apparent 'U-turn' when implementing planned interventions. In unpacking this within the CoP, it was suggested that the parent may have been experiencing grief in accepting the child's current circumstances, and the discussion around modifying the class programme could have triggered that grief. Having this extra perspective helped the RTLB to reframe the issue, and move forward with a slightly altered and revised approach. She was able to think 'outside' of herself. The value of this approach is clearly evidenced by the literature (Pollard, 1997; Reynolds, 2011; Ross, Bondy \& Kyle, 1993; Smyth, 1993) and as Sparks-Langer and Colton (1991) state, "beliefs must be examined critically from various perspectives to allow for a flexible and thoughtful approach to teaching" (p. 43).

A further benefit of reflecting within a community of practice is using communication to clarify one's thinking. When sharing thoughts and ideas as part of a collective activity, a person has to structure their thinking to express it coherently. This action forces us to communicate clearly so that others can understand and respond appropriately (Enfield \& Stasz, 2011). In essence, it changes vague scattered notions into lucid well-reasoned thoughts. One of the CoP members noted "by articulating thoughts, it clarifies your thinking" (CoP member, 30 August, 2012). This clearer, systematic picture was also useful for the 
CoP as it enabled group discourse around hypotheses and potential actions. Emery (1996), states that "oral language can promote exploration and extension of teacher knowledge and teacher self-confidence to generate knowledge about teaching, two aims of reflective practice" (p.110).

Alongside dialogue within a community sits another benefit to reflection within a CoP. It provides some accountability for follow-up action, as insights are only beneficial if they lead to further action (Harrison, Lawson \& Wortely. 2005). At each CoP session, questions were asked regarding previously discussed cases and their progress. These questions were born out of a genuine concern for CoP members rather than checking up on practice, and prompted further reflection about any new actions. The purpose of reflective practice is that through 'reflection plus action' we develop, refine and improve our practice (Harrison et al. 2005). This accountability toward action supports that purpose.

\section{CONCLUSION}

In terms of RTLB practice, using the Reflective Hub process and having a multi-lens approach to reflection and casework has a number of advantages. It encourages clear articulation of analysis and decisions, which are key components of the RTLB practice sequence. Being able to express ideas and thoughts within a group enables RLTB to have a clearer and deeper understanding of the casework undertaken. The CoP questioning and discussion provides a method to clarify thoughts and therefore create a stronger platform upon which to base one's action. The hub was effective in promoting deeper levels of reflection. It provided a collaborative perspective to RTLB work and challenged underlying assumptions and beliefs. The experience of reflecting within a CoP illustrated in a practical manner how quality reflection can positively impact RTLB practice. It brings the concept of learning with and from others to life.

\section{REFERENCES}

Edwards, G., \& Thomas, G. (2010). Can reflective practice be taught? Educational Studies, 36(4), 403-414.

Emery, W.G. (1996). Teachers' critical reflection through expert talk. Journal of Teacher Education, 47(2), 110-119.

Enfield, M., \& Stasz, B. (2011). Presence without being present: Reflection and action in a community of practice. Journal of the Scholarship of Teaching and Learning, 11(1), 108-118.
Hannant, B., Lim, E.L., \& McAllum, R. (2010). A model of practice in special education: Dynamic ecological analysis. Kairaranga 11(2), 28-32.

Harrison, J., Lawson, T., \& Wortely, A. (2005). Facilitating the professional learning of new teachers through critical reflection on practice during mentoring meetings. European Journal of Teacher Education 28(3), 267-292.

Larrivee, B. (2000). Transforming teaching practice: Becoming the critically reflective teacher. Reflective Practice, 1(3), 293-307.

Ministry of Education. (2011). Resource teacher: Learning and Behaviour (RTLB): Policy and toolkit. Wellington: Ministry of Education.

Pollard, A. (1997). Reflective teaching in the primary school: A handbook for the classroom (3rd ed.). London: Cassell.

Reynolds, M. (2011). Reflective practice: Origins and interpretations. Action Learning: Research and Practice, 8(1), March, 5-13.

Ross, D., Bondy, E., \& Kyle, D. (1993). Reflective teaching for student empowerment: Elementary curriculum and methods. New York: MacMillan.

Schön, D. (1987). Educating the reflective teacher. San Francisco: Jossey-Bass Inc.

Smyth, J. (1993). Reflective practice in teacher education and other professions. Keynote address to fifth National Practicum Conference, McQuarrie University, Sydney, 4 February.

Sparks-Langer, G. M., \& Colton, A. C. (1991). Synthesis of research on teacher's reflective thinking. Educational Leadership, March, 37-44.

Scales, P. (2008). Teaching in the lifelong learning sector. Maidenhead: McGraw-Hill Open University Press.

The New Zealand Teachers Council. (2009). Registered Teacher Criteria. Retrieved May 09,2013 from http://www.teacherscouncil.govt.nz/ content/registered-teacher-criteria

Wenger, E. (2009). Communities of practice: A brief introduction. Retrieved 12 July, 2011, from http:// www.ewenger.com/theory/ 


\section{AUTHOR PROFILES}

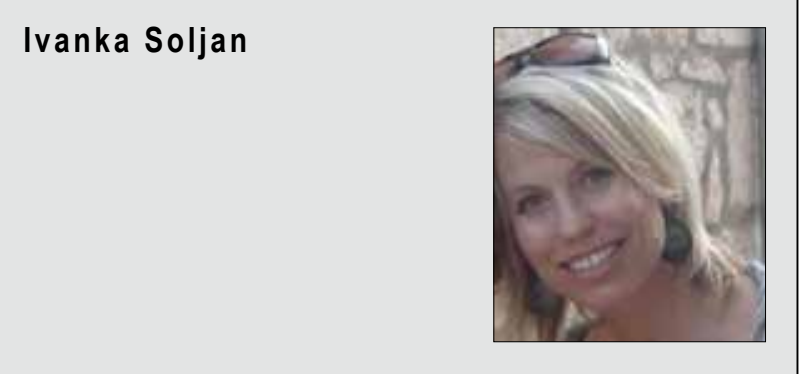

Ivanka Soljan is employed as a Resource Teacher: Learning and Behaviour in the Tuawhitu o Akarana Cluster in Central Auckland. Prior to this role she has spent a number of years working in primary and intermediate schools as a classroom teacher and in specialist positions. Along with her commitment to collaborative problem-solving, she also has an interest in social-emotional literacy and how this impacts on students' cognitive processes.

\section{Email:}

ivankartlb@mayroad.school.nz

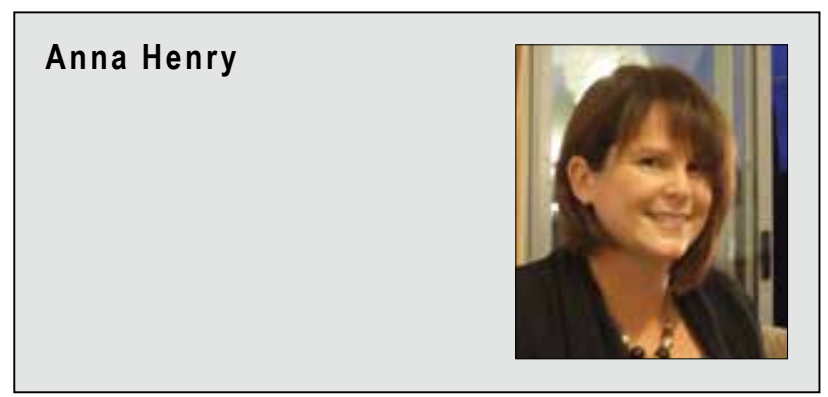

Anna Henry works as a Resource Teacher: Learning and Behaviour Practice Leader for Cluster 9 in the Mangere/Otahuhu area of South Auckland. She spent many years working in primary school settings pursuing her interest in planning and catering for students with high learning needs, through roles such as specialist teacher, special needs coordinator and as part of senior management teams. An area that she is particularly interested in is peer coaching as a tool for reflective practice.

\section{Email:}

ahenrysoutherncross@gmail.com

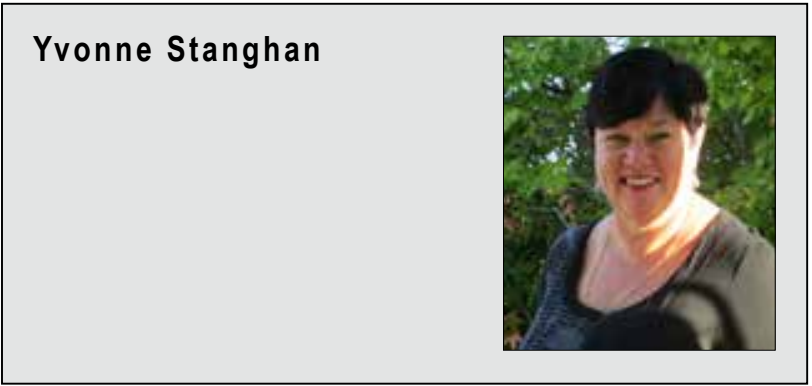

Yvonne Stanghan is a Resource Teacher: Learning and Behaviour in the Manawanui Cluster in the Papatoetoe/Otara area. She has been in this role since 2008. Yvonne has recently graduated from the new qualification for RTLBs, the Specialist Teaching Diploma, through Massey University. She has a strong interest in literacy and the process of achieving equitable access to quality literacy teaching and learning for all students.

\section{Email:}

yvonnes@papatoetoeint.school.nz 